\title{
Sea-level Rise Vulnerability of Mangrove Forests on the Micronesian Island of Pohnpei
}

\section{Introduction}

The mangrove forests across the Federated States of Micronesia provide critical resources and contribute to climate resilience. Locally, mangrove forests provide habitat for fish and wildlife, timber, and other cultural resources. Mangrove forests also protect Micronesian communities from tropical cyclones and tsunamis, providing a buffer against powerful waves and winds. Mangrove forests in Micronesia can store 700-1,800 metric tons of carbon per hectare (Donato and others, 2011), contributing to the estimated 5-10 billion metric tons of carbon stored by mangroves around the world (Alongi, 2018). This carbon storage is essential for global climate resilience.

Mangrove forests and the benefits these ecosystems provide are threatened by accelerating sea-level rise and human activities. Healthy mangrove forests are resilient systems and have kept pace with some amounts of sea-level rise, but rapid sea-level rise could outpace the mangroves' ability to adapt. Degraded mangroves are at greater risk where natural processes have been altered. Overharvest and clearing of timber, infrastructure development, and altered hydrology are just a few of the human activities that can damage mangrove forests.

\section{Modeling Mangrove Dynamics}

Scientists and land managers from the U.S. Geological Survey (USGS), U.S. Department of Agriculture Forest Service, U.S. Fish and Wildlife Service, Micronesia Conservation Trust, Conservation Society of Pohnpei, and the Pohnpei Forestry collaborated to study how mangroves in Micronesia will respond to sea-level rise over the coming century, beginning with the island of Pohnpei (Buffington and others, 2021). The researchers developed a mathematical model to project the future of mangrove forests under different sea-level rise scenarios to inform local planning and decision making.

The model incorporates the relationships between the ocean, mangroves, and soils, showing how a change in sea level translates to changes throughout the ecosystem (fig.1). Elevation, relative to sea level, determines which tree species will thrive at a particular location and influences the biomass of the forest. When trees drop leaves, turn over roots, or die, their biomass decays and becomes part of the soil. Along with mineral inputs, biomass builds up the soil (accretion) and raises the elevation of the soil, counteracting the effects of sea-level rise. Mangrove forests can be resilient to sea-level rise if accretion rates outpace sea-level rise or if the forests have room to migrate inland to high ground.

The model incorporates these processes into equations that predict how elevation and mangrove species composition will change under a range of global sea-level rise scenarios: 37 centimeters (cm; RCP 4.5), $52 \mathrm{~cm}, 67 \mathrm{~cm}$ (RCP 8.5), or $117 \mathrm{~cm}$ of sea-level rise by 2100 . The sea-level rise scenarios are based on possible global carbon dioxide $\left(\mathrm{CO}_{2}\right)$ emission scenarios outlined by the Intergovernmental Panel on Climate Change, reflecting the resulting rise in sea level due to thermal expansion and the melting of ice as global temperatures rise. The modeling framework was calibrated with extensive field datasets from Pohnpei's mangroves, including accretion rates derived from soil cores, soil surface elevation tables, over 300 forest inventory surveys, water-level monitoring, and elevation surveys (fig. 2).

\section{Management Takeaways}

- Mangroves on the island of Pohnpei are likely to be resilient to low and moderate rates of sea-level rise over the coming decades if they remain intact and healthy.

- Under high rates of sea-level rise, the mangroves could see substantial changes to species composition and loss of mangrove forests at island edges.

- Mangroves on the leeward southwest side of Pohnpei are the most at-risk to higher rates of sea-level rise.

- The new modeling approach used to project sea-level rise impacts for Pohnpei's mangroves can be applied to other mangroves in the Pacific.

- The continued monitoring and study of the mangrove forest will allow the tracking and further understanding of sealevel rise impacts to inform adaptive management. 


\section{Model Projections-Resilience and Change}

Model projections show that mangroves on the island of Pohnpei are likely to be resilient to low and moderate rates of sea-level rise over the coming decades if they remain intact and healthy (fig. 3). Under $37 \mathrm{~cm}$ or $67 \mathrm{~cm}$ of sea-level rise, predictions showed limited changes in species composition over the next 30 years, with some expansion of low elevation species and possible losses of high elevation species by 2100 (in some parts of the island).

However, under the most extreme sea-level rise scenario, $117 \mathrm{~cm}$ of sea-level rise, mangrove elevation decreased substantially relative to mean sea level, with more drastic changes in the tree species composition starting in 2060 and loss of mangroves by 2100 . Vulnerability to sea-level rise varied across the island, with mangroves on the leeward side of the island generally the most at-risk to high rates of sea-level rise.

The model's predictions are limited to the effects on elevation and tree species composition. The potential effects of sealevel rise on other parts of the mangrove ecosystem, such as bird and fish communities, are currently unknown.

\section{Summary}

There remains a great deal of uncertainty as to how quickly and how much sea level will rise over the next century. Understanding how different mangroves could respond to a range of sea-level rise scenarios will allow stakeholders to develop plans and management actions to (1) conserve mangrove forests that are resilient to sea-level rise over long periods of time, (2) develop strategies to increase the resilience of mangroves that are vulnerable to sea-level rise, and (3) provide educational outreach to local communities. The new modeling approach developed by the USGS and partners provides projections of sea-level rise impacts for the island of Pohnpei. The approach is transferable across the Pacific region and, at the time of this report, is being applied to the Micronesian island of Kosrae. Maintaining the current and relatively undisturbed state of mangroves around Pohnpei is important to maintain forest resilience to sea-level rise and preserve the benefits that these forests provide to local and global communities.

By Karen M. Thorne and

Kevin J. Buffington

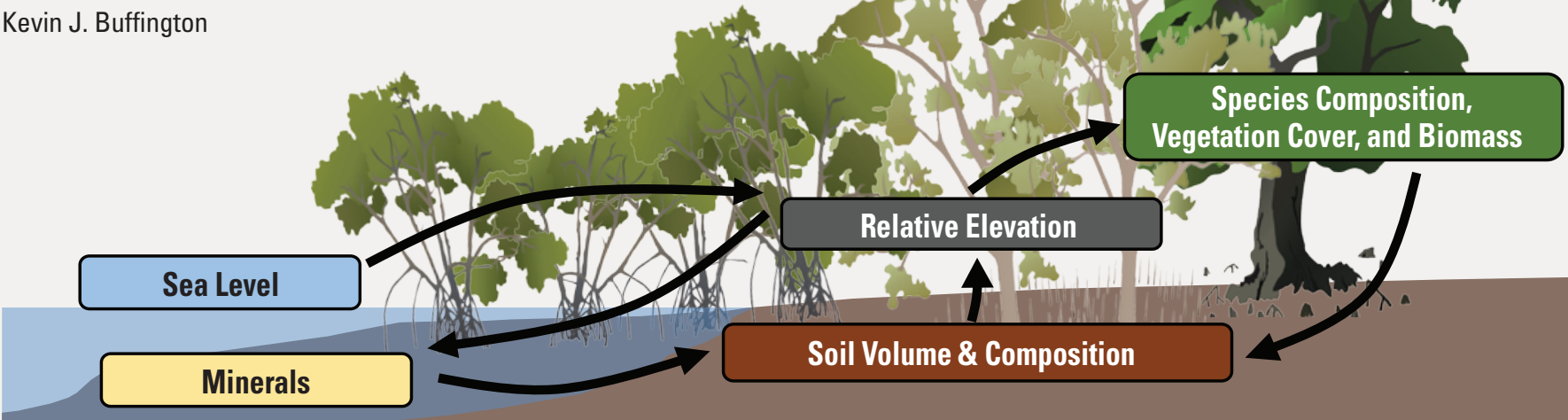

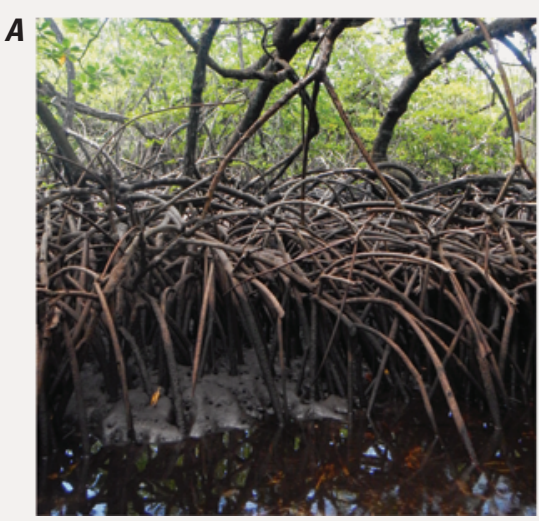
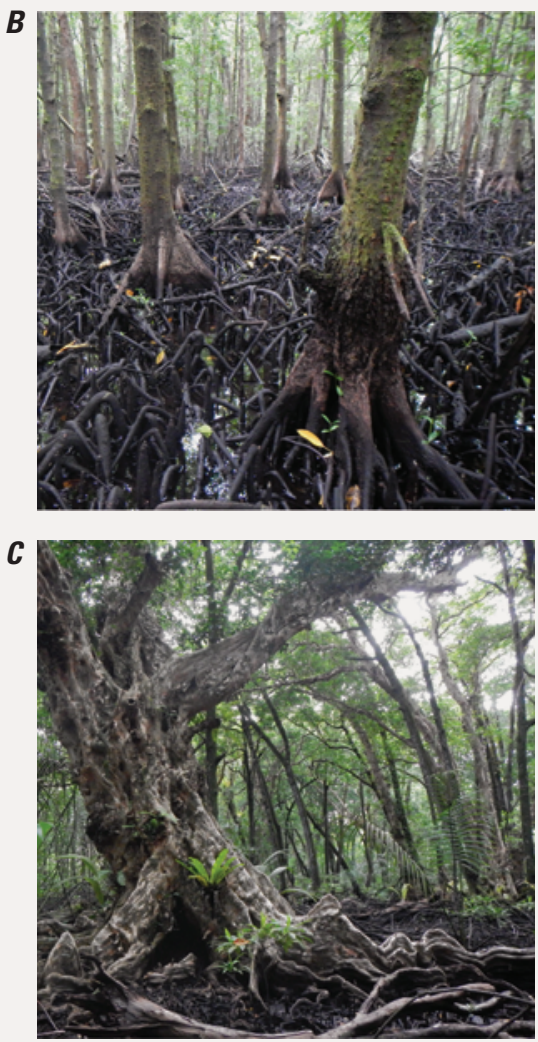

Photographs by Kevin Buffington, U.S. Geological Survey

Figure 2. Examples of low elevation $A$, generalist; $B$, high-elevation; and $C$, mangrove species.

Illustration by Kevin Buffington and Alexandra Weill, U.S. Geological Survey. Tree stock images by Tracey Saxby and Christine Thurber, used with permission.

Figure 1. Conceptual model of mangrove dynamics. 


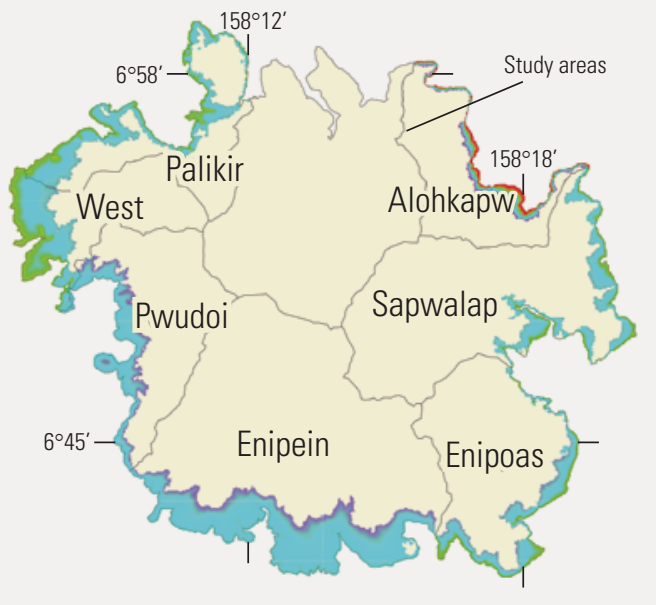

2060, 37-cm sea-level rise

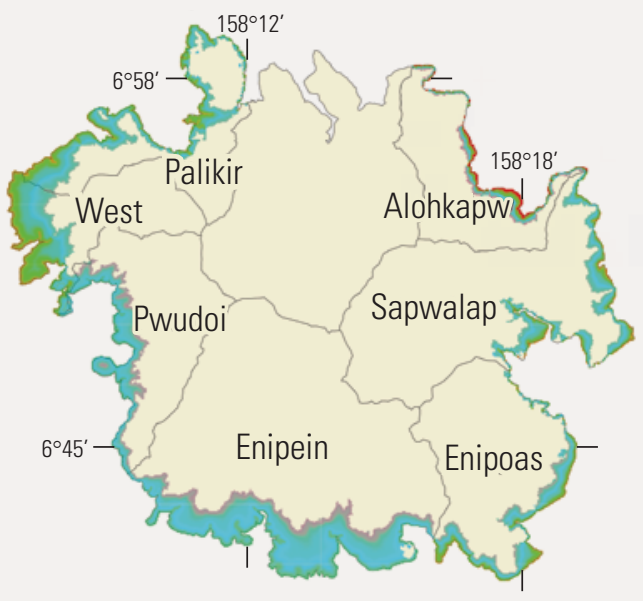

2060, 117-cm sea-level rise

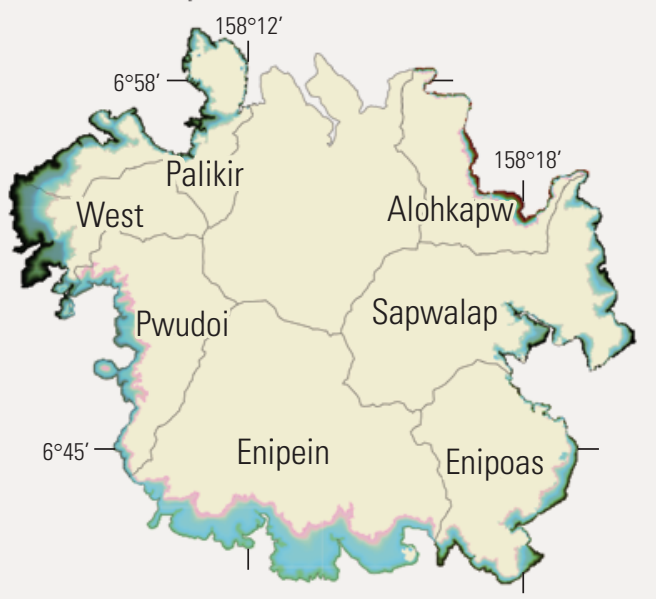

Polygons from Digital Atlas of Micronesia, principal watershed dataset, accessed at https://islandatlas.org. Universal Transverse Mercator, zone 57; WGS 1984.
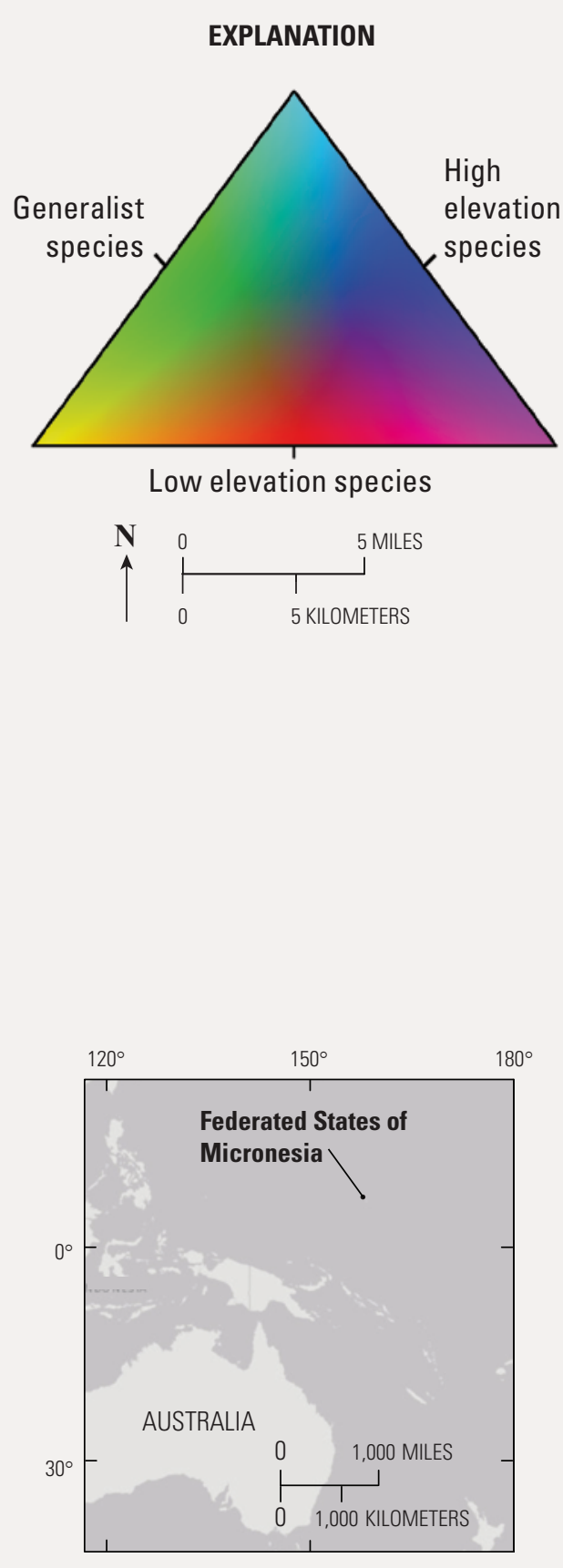

Background image is the intellectual property of Esri and is used herein under license. Copyright (C) 2014 Esri and its licensors. All rights reserved.

Figure 3. Projected mangrove species distribution in 2020 and in 2060 under 37 centimeters (cm) and 117-cm sea-level rise scenarios. Areas of mangrove loss appear in black. 


\section{For more information concerning the research in this report, contact}

Karen M. Thorne, Western Ecological Research Center U.S. Geological Survey

Davis Field Station

One Shields Avenue

University of California

Davis, California 95616

(916) 502-2996

Email: kthorne@usgs.gov

https://www.usgs.gov/centers/werc

\section{References Cited}

Alongi, D.M., 2018, Mangrove forests, in Blue Carbon-

SpringerBriefs in Climate Studies: Springer, Cham, p. 23-36, https://doi.org/10.1007/978-3-319-91698-9_3.

Buffington, K.J., MacKenzie, R.A., Carr, J.A., Apwong, M., Krauss, K.W., and Thorne, K.M., 2021, Mangrove species' response to sea-level rise across Pohnpei, Federated States of Micronesia: U.S. Geological Survey Open-File Report 2021-1002, 44 p., https://doi.org/10.3133/ofr20211002.

Donato, D.C., Kauffman, J.B., Murdiyarso, D., Kurnianto, S., Stidham, M., and Kanninen, M., 2011, Mangroves among the most carbon-rich forests in the tropics: Nature Geoscience, v. 4, p. 293-297, https://doi.org/10.1038/ngeo1123.

\section{Partners}
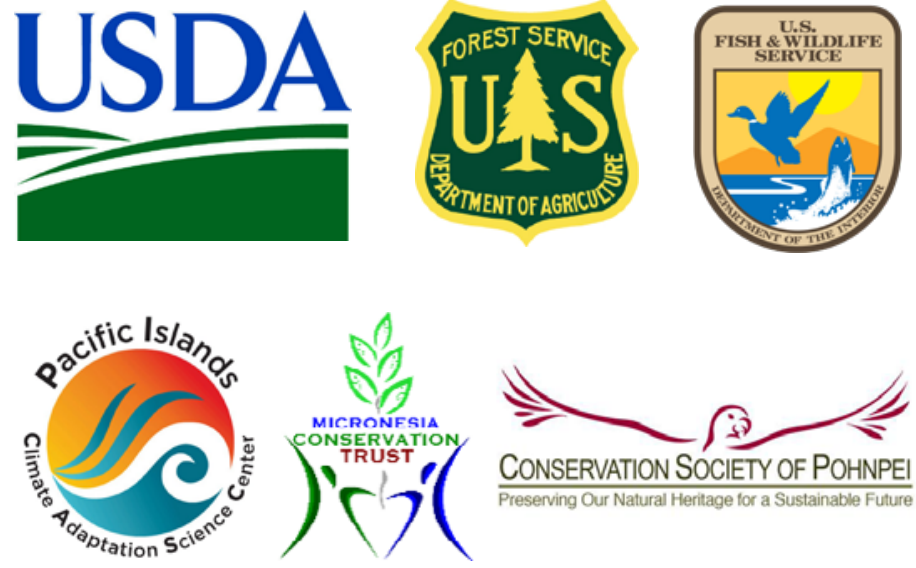

CONSERVATION SOCIETY OF POHNPEI Presenving Our Natural Hertiage for a Sustainable Future 